\title{
Burnout and Depression in Medical Assistants in State-Owned Healthcare Institutions in Romania
}

\author{
Ágnes SÁNTHA \\ Sapientia Hungarian University of Transylvania \\ Cluj-Napoca, Romania \\ santhaagnes@ms.sapientia.ro \\ Réka LUKÁCS-MÁRTON \\ Sapientia Hungarian University of Transylvania \\ Cluj-Napoca, Romania \\ lmrekus@gmail.com \\ István VINGENDER \\ Semmelweis University \\ Budapest, Hungary \\ vingenderi@se-etk.hu
}

\begin{abstract}
Similarly to other countries in the Eastern European Region, the situation of medical assistants in Romania is fairly difficult. Due to the lack of personnel, health professionals are typically overwhelmed with work. The Quality of Life Research Centre at Sapientia Hungarian University of Transylvania conducted a non-representative survey among medical assistants in Romanian state-owned healthcare institutions. The sample size is 312 Romanian and Hungarian speaking nurses from six counties. The present study problematizes the mental health of medical assistants, more precisely burnout and depression, along demographic, social, and labour market features. The determinants of burnout and depression are being searched for among these structural and situational variables, and their controlled impact is being assessed with linear regression. Results indicate an excessive risk of burnout and depression for nurses with lower-qualification working in outpatient care. Differences in the mental health of medical assistants echo to a large extent social inequalities, so that controlled for covariates, household income has a significant impact upon burnout and depression. From demographic agents, the protective effect of partnership is outstanding, and the number of supportive relationships is a protective factor of its own right against both burnout and depression. Female assistants are more at risk for depression but not for burnout, whereas workload increases the risk of burnout but not of
\end{abstract}


depression. The analysis takes sides of the distinctness of burnout and depression. Although both syndromes are largely influenced by social features, burnout seems to be more situationally influenced whereas depression more structurally affected.

Keywords: healthcare professionals, nurses, burnout, depression, WHO-5 Well-Being Index

\section{Introduction}

Healthcare personnel, software developers, athletes, and lawyers are identified among professions at high risk of burnout and depression (Bria et al. 2014). The reasons for considering healthcare personnel to be a high-risk profession for these syndromes are work overload and emotionally overwhelming work. Burnout rates among healthcare professionals are higher than in the general population (Shanafelt et al. 2012). As a result, healthcare professionals' health-related quality of life is lower than the average, and it is even lower among those who reported higher levels of burnout (Suñer-Soler et al. 2012). For instance, in Hungary, the prevalence of medium-level burnout among medical assistants is as high as $35 \%$ (Ádám et al. 2015). By the same token, in the European nurse population, an increase of only one patient per nurse increases the mortality risk by as much as 7\% (Zander et al. 2016).

In Romania, like in all service societies, medical assistants (nurses) are one of the largest professional groups. This is so even in spite of the fact that compared to 1990 the number of medical assistants decreased by $25 \%$, with a dramatic loss between 2007 and 2012. In the meantime, the number of patients increased by $12 \%$, which led to an increase of $40 \%$ in the service duties (Rotilă et al. 2014). The workload of healthcare professionals is immense: 1,000 patients benefit from 2 physicians and 4 nurses (Bria et al. 2013). One in four medical assistants performs unpaid work, more than half of them constantly work overtime, $40 \%$ of assistants claim that their overtime work remains unpaid either by financial remuneration or with free days, and $21 \%$ had not benefitted from a vacation in the previous five years (Rotilă et al. 2016). Although in 2018 and 2019 substantial financial benefits were offered for healthcare personnel in the state-owned units, the extensive workload is still typical.

A recent Romanian study assessed higher levels of burnout among personnel in state-owned hospitals than in private units (Makkai 2018). Our analysis proposes to identify the determinants of burnout and depression in medical assistants employed in Romanian state-owned healthcare units. These determinants are being searched for among occupational, social, and demographic features. By identifying the employee groups that are most at risk, the authors are hoping to contribute to the improvement of their situation. 


\section{Theoretical Aspects. Burnout Models}

The most commonly employed measure for burnout is without doubt the Maslach Burnout Inventory (MBI). One of its versions (MBI-HSS) is intended precisely for workers employed in health and social services. Maslach and Jackson (1986: 1) first defined burnout as "a syndrome of emotional exhaustion, depersonalisation, and reduced personal accomplishment that can occur among individuals who do 'people work' of some kind".

The psychometric properties of the three-dimensional MBI-HSS became the target of criticism due to three considerations (Loera et al. 2014). First, its construct validity has been questioned since the late 1980s, when analyses pled for a onedimensional model, i.e. for the reconceptualization of the inventory to regard only emotional exhaustion as the essence of burnout, while accomplishment and depersonalization to be considered only related variables to burnout (KoeskeKoeske 1989). Other scholars argued for a two-dimensional construct which includes exhaustion and depersonalization (Green et al. 1991), even specifically among healthcare professionals (Kalliath et al. 2000), or for a global burnout factor and a specific personal accomplishment factor (Mészáros et al. 2013). In several empirical studies, the components of the burnout scale cross-loaded on multiple factors that compromised the integrity of this widely used measurement tool. Second, the reliability of the instrument was questioned (Wheeler et al. 2011). Third, there might be a cultural bias in the MBI: it was developed in the North-American context, so that the instrument's different behaviour in other samples may be caused by the linguistic and cultural heterogeneity of the samples (Maslach et al. 2001). For instance, North Americans may be more likely than Europeans to give extreme answers to items or to express cynicism, and the initial items may have lost something from their original meaning during translation (Ziegler-Bensch 2013).

The Job Demands-Resources Model of burnout underpins the conceptual framework of an alternative measurement tool for the Maslach Burnout Inventory, namely the Copenhagen Burnout Inventory. In this European model, examples for job demands implying costs are work overload, heavy lifting, interpersonal conflict, and job insecurity, whereas job resources are feedback, job control, and social support (Demerouti et al. 2001). The core of burnout is fatigue and exhaustion, with the addition that these are attributed to specific domains or spheres in the person's life. One such domain is work and a more specific domain is client work (Borritz et al. 2005). The questionnaire entails three sub-dimensions: personal burnout, workrelated burnout, and client-related burnout. The three scales are used independently in accordance with the populations being studied and the theoretical questions being elucidated.

A further well-established explanation of burnout is the Conservation of Resources Theory, i.e. the COR (Hobfoll 1989, Hobfoll-Shirom 1993). When 
individuals experience a loss of resources, their response is to limit the impact of that loss through energy conservation. Stress occurs either when resources are threatened or when resources are lost or when individuals do not obtain the return they were hoping for from the resource investment. The aim of individuals is to protect themselves from resource loss, so that employees are the most sensitive to work-related stress that threatens their resources. The Shirom-Melamed Burnout Measure (SMBM), designed to assess the definition of burnout according to the Conservation of Resources Theory, entails the dimensions of physical fatigue, emotional exhaustion, and cognitive weariness.

Lastly, the existential psychodynamic perspective offers an insight into the background of career choice and, implicitly, to the emergence of burnout. According to Malach-Pines (2000), people choose an occupation that enables them to replicate significant childhood experiences, and they try to find existential significance through their work. Burnout occurs when individuals experience a failure in their existential quest, and it is related to the lack of control, which, in turn, has its origin in the childhood experiences of lack of control.

\section{Healthcare Professionals' Burnout, Depression, and Their Consequences}

The literature is inconclusive as to whether burnout and depression are the same or distinct constructs, and there is evidence for both views (Bianchi et al. 2015, Koutsimani et al. 2019). The fact is that emotional exhaustion, the core component of burnout, is positively correlated with depressive symptoms (Bianchi et al. 2013, Ahola et al. 2014). Burnout and depression appear to share a common biological basis (Bakusic et al. 2017), and the symptoms of burnout are similar to those of depression (Tizón 2004).

Other studies reveal that burnout and depression do not overlap with each other (Bakker et al. 2000, Toker-Biron 2012). The decisive argument for this is the fact that burnout is work-related and situation-specific, whereas depression is contextfree and pervasive (Freudenberger-Richelson 1980, Maslach et al. 2001).

In spite of the above uncertainties, it is a fact that burnout is one of the early indicators of depression in Hungarian healthcare professionals (Ádám et al. 2015), and both syndromes are endangering mental health, so studying them in the population of medical assistants is the more important as its consequences are detrimental in several respects.

Healthcare professionals' burnout and depression are basically discussed with regard to three major outcomes: health professionals' mental and physical health, workplace victimization in the form of verbal or physical aggression from patients and their relatives, and the worsening quality of care for patients. 
Psychiatric morbidity is closely related to burnout (Visser et al. 2003), and having high levels of burnout leads to a deterioration in health both physically and mentally, but even stronger mentally. However, the causal relationship still needs some investigation as it might be the case that healthcare workers with low perceived health show symptoms of burnout as manifestations of their general symptoms or that several causes are simultaneously responsible for the increase of burnout scores and worsening health - e.g. in Spain nurses have worse perceived health than physicians (Suñer-Soler et al. 2012).

Aggression from patients and their family members seems to be an occupational hazard among medical assistants, most frequently among younger professionals. In Hungary, one third of all hospital incidents involve medical assistants as victims, which is almost five times the rate which occurs among medical doctors (HarmatCzárán 2008). Verbal aggression is very common, but every fourth or fifth nurse experiences physical aggression and injury on the part of patients (Irinyi-Németh 2017). Similar victimization rates were reported in Italy (Luciani et al. 2016). It is important to mention that in both countries nurses reporting high levels of burnout, fatigue, and stress are more likely to become victims of aggression (Luciani et al. 2016, Irinyi-Németh 2017).

Spanish and Italian studies argue that, in general, the incidence is higher in large hospitals, especially in services such as accident and emergency and psychiatry (Gascón et al. 2009, Luciani et al. 2016), and in spite of the high rates of victimization reporting it to the authorities is still very scarce (Luciani et al. 2016). Studies on workplace victimization in Romania are scarce. However, the one existing so far, conducted at the emergency care unit in a central hospital, reveals that healthcare professionals consider that exposure to violence is part of their job (Gal et al. 2013).

Burnout and depression influence work performance in a negative way. According to the vast majority of research studies, poor mental well-being in healthcare personnel measured with a wide range of definitions induces worse patient safety. The poor patient safety outcomes consist first and foremost of medical errors (Hall et al 2016). In the case of Romanian nurses, a recent study showed that burnout mediated the relationship between job demands and quality of care (Spânu et al. 2013).

Besides the bad quality of care provided by burnt-out healthcare staff, there are further detrimental effects of this syndrome on the health system due to the high rates of poor work ability associated with it as well as due to the increase in sickness-related absenteeism and high staff turnover. These consequences were assessed for Hungarian healthcare professionals (Pálfi et al. 2008). In Sweden, a longitudinal study revealed the connection between exhaustion and reduced work ability (Glise et al. 2010). Globally, mental disorders are the second largest cause of illness and of incapacity to work, and in the first decades of the twenty-first century their relative share increased in the global burden of diseases, particularly in the upper-middle- and high-income countries (Rehm-Shield 2019). 


\section{The Determinants of Burnout and Depression in Medical Assistants. Variable Selection}

The departure point for the selection of variables to be included in the analysis consists of the findings of previous international and Romanian studies on the topic. In the literature, the predictors of burnout and depression are grouped into psychosocial, organizational, and occupational factors. However, meta-analyses highlight occupational factors as the strongest (Alarcon 2011, Johari-Omar 2019) determinants of burnout, so that the below description of the variable selection rationale starts with presenting empirical evidence for the primacy of labourmarket-related determinants.

To start with, the predictors of burnout in previous empirical research in different countries are summarized. First and foremost, as revealed by meta-analysis in several countries and healthcare settings, burnout is related to both physical and emotional fatigue originating from long working hours and excessive workload (Zubairi-Noordin 2016). The lack of personnel typical for Romanian healthcare system renders the workload of employees even more serious (Rotilă et al. 2014, 2016) and predicts high levels of burnout for personnel.

Then, there is evidence for the differences among the various levels of burnout that relate to the activity domain. In the United States, Shanafelt et al. (2012) measured the highest rates of burnout among physicians at the front line of care access such as family medicine, general internal medicine, and emergency care. A recent Spanish study assessed that emergency care unit workers are more susceptible to burnout, whereas the syndrome is present to a lesser extent in the specialized outpatient care units (Palenzuela et al. 2019). Among Hungarian medical assistants, those working in intensive care have the highest scores for burnout, followed by nurses in longterm care. Active ward nurses show the lowest scores for burnout (Pálfi et al. 2008). To date, until the present study, there has been no empirical material on Romanian nurses with regard to activity domain and burnout scores.

Among occupational determinants, the precariousness of the contractual status is less researched; however, it is confirmed that it predicts burnout (Gonçalves et al. 2019; Zarei et al. 2019).

Next to organizational determinants, there are demographic characteristics to impact upon burnout. Surprisingly enough, the length of employment relationship, which strongly correlates with age, behaves contrary to rational expectations. Thus, burnout is higher among young employees, whereas more experienced professionals are less likely to show severe burnout symptoms. In the United States, Maslach et al. (2001) and Schaufeli and Enzmann (1998) assessed the negative correlation of burnout and organizational tenure (age) in human service work. The meta-analysis of Brewer and Shapard (2004) also indicated that in some sectors in the United States there was a small negative correlation between employee age and emotional 
exhaustion, one of the components of burnout. Older healthcare professionals have better burnout scores in Hungary (Ádám et al. 2015), in Palestine (Hamdan-Hamra 2017), and in Iran (Zarei et al. 2019).

There are three main explanations for the negative association between organizational tenure and burnout scores. Firstly, at a younger age, horizons may be uncertain and job security lacking. Secondly, those who suffered from burnout at a younger age may have dropped out from their job and changed their career trajectory (Randall 2007). Thirdly, older workers may have learned to minimize their burnout risks to manage occupational stress, and they gained self-confidence over time. Thus, longer employment relationship increases self-efficacy (Deutsch et al. 2015). Career advancement also increases their job satisfaction, and adaptation to work environment renders older nurses more resistant to burnout (Zarei et al. 2019).

The relationship between gender and burnout is inconclusive. In Hungarian medical assistants, male gender is a risk factor for burnout (Ádám et al. 2015), whereas in Iranian professionals it is not (Zarei et al. 2019). The possible gender difference in burnout may reflect differences in roles and occupations (SchaufeliGreenglass 2001).

Single health professionals are more likely to suffer high levels of burnout. In Iran, their risk ratio is about three times higher than for married people (Zarei et al. 2019). In the United States, unmarried health sector workers (especially men) seem to be more exposed to burnout than those married (Schaufeli-Enzmann 1998). According to the evidence of a meta-analytic study, family background serves as a protective factor against burnout in several countries and healthcare settings (Molina-Praena et al. 2018).

Social support works against burnout. An empirical study rooted in the model of Job Demands-Resources conducted among Irish midwives concluded that the relational resources of employees predicted work engagement and high levels of motivation, which, in turn, decreased burnout (Freeney-Fellenz 2013). Bridgeman et al. (2018) argue that social support prevents burnout in the United States healthcare professionals. The association is revealed in further countries and healthcare settings by meta-analytic studies (Molina-Praena et al. 2018). In Hungary, parenting medical assistants have fewer burnout complaints than childless ones with similar social and organizational profile (Ádám et al. 2015).

There is a social gradient with respect to burnout. Greek healthcare professionals with higher levels of education and income reported less burnout (Tachtsoglou et al. 2018). In the present study, socioeconomic status is measured by a series of items including educational level, organizational tenure, and income.

Further causes for burnout were found to be relationship with co-workers and lack of autonomy and control, which operate in the developing country of Pakistan (Zubairi-Noordin 2016) and in the developed countries as well, e.g. the United States (Bridgeman et al. 2018). Negative work-home interface is detrimental for 
burnout in Portuguese health professionals (Gonçalves et al. 2019) and in Swiss health workers (Häusler et al. 2018).

In most burnout models, the syndrome is closely related to work, whereas depression is context-free (Freudenberger-Richelson 1980, Maslach et al. 2001). Accordingly, among predictors of burnout, studies found less occupational and more social and demographic features.

In the general Irish population, research reveals the lack of a substantial age effect in depression (Delaney et al. 2017). However, in the special population of Pakistani healthcare professionals, older assistants have more favourable depression scores (Waqas et al. 2015).

The role of gender in depression is a well-established fact, women having more depressive complaints than men. The gender difference in depression measured with the CES-D 8 questionnaire is significant in 25 European countries (Van de Velde et al. 2010a). However, there are important variations among countries, and gender differences in depression are the largest in some of the Eastern and Southern European countries and smallest in Ireland, Slovakia, and some Nordic countries (Van de Velde et al. 2010a). In the Irish population, depression measured exactly with the same WHO-5 scale as to be used in the present study did not reveal gender differences (Delaney et al. 2007). To look closer at the specific population of healthcare professionals, males reported to have fewer depressive complaints than women in a Pakistani healthcare population (Waqas et al. 2015), but, surprisingly, among Hungarian medical assistants, male gender was a risk factor for depression (Ádám et al. 2015).

In both genders, lower risk of depression is associated with marriage and cohabiting with a partner (Van de Velde et al. 2010b) and with social support in general (Delaney et al. 2007). Just as in the general population, partnership is undoubtedly beneficial and protective against depression in healthcare professionals, too. Among Hungarian nurses, those having a partner account for less depressive symptoms than those who are divorced, separated, or single (Ádám et al. 2015, Deutsch et al. 2015).

Although to a lesser extent than burnout, depression is reported to be affected by some occupational factors such as: job satisfaction, self-efficacy, and achievement in an Australian sample of maternity nurses (Rodwell-Munro 2013); occupational stress and work engagement in Indian populations of medical doctors and assistants (Kumar et al. 2018); authentic leadership in Irani healthcare providers (RahimniaSharifirad 2014).

To sum up, in both burnout and depression research, there are predictors which are either universal and unequivocally confirmed or work differently, often contradictorily in different healthcare settings. The novelty of the present analysis is that it assesses the determinants of burnout and depression at the same time, on the same sample of Romanian nurses, and thus fruitfully contributes to the debate on the origin of both syndromes. 
The aim of the statistical analysis below is to identify the key determinants of burnout and depression among medical assistants in Romanian state-owned healthcare units. Keeping in mind the wide range of the above listed risk factors, the study includes those variables that have primacy in influencing burnout and depression and that were technically allowed for by the relatively restricted data. The analysis includes the same alleged predictors for both syndromes.

\section{Methodology}

For the purposes of this study, a standardized questionnaire was used. The tool was first compiled by the Semmelweis University (Faculty of Health Sciences Research Group), Budapest, and entails standardized items for various measurements (Vingender et al. 2018). Romanian data were collected in the winter of 2017-2018 on a non-representative sample of 312 Hungarian- and Romanian-speaking medical assistants from six Romanian counties (Mureş, Satu Mare, Sălaj, Bihor, Harghita, Covasna). Classic paper-based questionnaires were completed at the workplace of the respondents, i.e. large state-owned hospitals and primary care units, with the permission and support of the national organization of medical assistants (OAMGMAMR). With the Hospital Board of Directors' approval, department chiefs were asked for authorization to administer the questionnaire to the nurses. The introductory text explained the aim of the research, the voluntary nature of participation, and the anonymity of the data collected.

Based on the arguments described in the literature review on the existing burnout measures, our research group tested a self-compiled, standardized, one-dimensional measurement tool for burnout. The Hungarian questionnaire was translated into Romanian language, too. Validation of the Romanian questionnaire took place with the forward-backward translation process, and experts produced the final version of the translation to make sure that the questionnaires in both languages are assessing the equivalent construct with an equivalent metric.

The questionnaire aimed at obtaining information on mental health with two indicators: a self-compiled burnout scale for measuring burnout and the WHO-5 well-being scale for depression (WHO 1998). Burnout was assessed with 15 items as follows: I have no mood to work; I am blue; I feel hopeless; I feel left alone; I have self-esteem problems; I feel anger; I experience inner anxiety; my behaviour is uncontrolled; I need to smoke; I need some alcohol; I need some tranquillizer; I don't even know who I really am; I have no plans; I have no future; I am not interested in others. The answer possibilities assess the frequency of these symptoms on a 4-point scale: never, once a month or less, a few times a month, almost every day. From the answers given to the questions, a non-weighted summated rating was 
used ranging from 0 to 45 , where the higher numbers represent more numerous and more frequent burnout complaints.

The WHO-5 has been found to have adequate validity in screening for depression, and it has good construct validity as a one-dimensional scale measuring well-being in general populations (Topp et al. 2015). The scale was assessed using non-weighted summated rating, according to the indications of the World Health Organization, the score 0 representing the worst and 100 the best imaginable well-being, that is, less depressive symptoms. Although, certainly, these scale scores do not replace a medical diagnosis, they do indicate the main tendencies in mental health.

A reliability test was performed on the questionnaire items for both scales. Cronbach's alpha values indicate that both the burnout and the depression (wellbeing) scales are good measurement tools in terms of internal consistency. The measure of internal consistency for Likert-type scales showed that the burnout scale attained good reliability $(\alpha=0.87)$ and the WHO-5 scale even excellent reliability $(\alpha=0.94)$. All items included in the analysis appeared to be worthy of retention as the deletion of none of them would have resulted in an increase of the internal consistency of the measure.

Descriptive statistics are used to reveal the burnout and depression scores of medical assistants across the working hours, activity domain, organizational tenure, length of the working relation, gender, partnership status, and the number of intimate social relations. Two-variable analysis (analysis of variance) reveals associations between assumed determinants on the one hand and burnout and depression scores on the other, whereas linear regression is called upon to assess the explanatory power of variables one by one, adjusted for the effect of all other covariates. The aim is to explain differences in the level of burnout and depression across important inequality variables.

The regression model searches among possible occupational, socioeconomic, and demographic determinants that significantly explain burnout and depression. These explanatory variables are: working hours, activity domain, income, age, gender, partnership status, and number of intimate social relations. In the explanatory model, the categorical variable activity domain was transformed into dummy variables. Organizational tenure is replaced with income because it largely correlates with it, and the measurement level of income (deciles) is more adequate in the regression model. Age is used as a proxy for the length of working relation due to methodological considerations, the former being a continuous variable better suited for linear regression.

During the regression analysis, the best fitting and most parsimonious causal model was found, using the variable selection procedure. Following standard procedure (Kleinbaum et al. 2007), the model was first simplified leaving out the non-significant interaction effects one by one. Thereafter, an automated variable selection algorithm was called upon. Since gender and age are a priori important 
in health research, they remained in the regression model throughout the whole model-building procedure. Apart from these two, the remaining variables were sorted out. Enter selection was used, the threshold being set at $5 \%$ for inclusion and at $10 \%$ for exclusion. The final model was subjected to multicollinearity diagnostics, monitoring the VIF and tolerance indicators.

\section{Sample Characteristics}

Typically, the female workforce is engaged in medical assistance activities, so it is not a surprise that $92.5 \%$ of the respondents are women and only $7.5 \%$ men. The age of the respondents ranges from 21 to 59 years. Most of them finished nursing professional school, one third have a university BA degree in nursing, and only a small minority obtained an MA. Most respondents work in the inpatient care $(58.5 \%)$, others in outpatient care units $(19 \%)$, in primary care $(16.3 \%)$, or home care $(6.2 \%)$. Our sample entails nurses (48\%), specialized nurses $(25 \%)$, head nurses $(21 \%)$, and nurse technicians (6\%). Typically, nurses work in several shifts in their main jobs $(62.3 \%)$, and every ninth of them has a second job, too. This implies high workload and an increased burnout risk.

\section{Results}

In the sample of medical assistants, the mean value on the burnout scale is 12.37 , while the mean value on the WHO-5 scale for depression is 68.28 points. To assess the two-variable associations between alleged determinants and mental health, analyses of variance are performed, which reveal the differences in the average number of burnout and depressive symptoms by workload (working hours), activity domain, organizational tenure, length of employment relationship, gender, partnership status, and social integration. 
Table 1. Two-variable associations of the burnout and depression scores with occupational, socio-economic, and demographic variables in medical assistants. $N$ = 308. Analysis of variance (ANOVA)

\begin{tabular}{|c|c|c|}
\hline Category & $\begin{array}{l}\text { Mean score on the } \\
\text { burnout scale }(0-45)^{1}\end{array}$ & $\begin{array}{l}\text { Mean score on the WHO- } \\
5 \text { scale for depression } \\
(0-100)^{2} \\
\end{array}$ \\
\hline Total sample & 12.37 & 66.28 \\
\hline Shorter work time & 10.27 & 67.00 \\
\hline Regular work time & 16.13 & 71.20 \\
\hline Longer work time & 14.44 & 70.53 \\
\hline ANOVA & $\begin{array}{l}\mathrm{F}=5.750, \mathrm{p}=.004 \\
\text { Eta squared }=.101\end{array}$ & $\begin{array}{l}\mathrm{F}=.680, \mathrm{p}=.509 \\
\text { Eta squared }=.011\end{array}$ \\
\hline Primary care & 9.80 & 71.73 \\
\hline Outpatient service & 13.57 & 61.60 \\
\hline Inpatient service & 12.52 & 73.24 \\
\hline Home care & 10.00 & 48.00 \\
\hline ANOVA & $\begin{aligned} \mathrm{F}=1.867, \mathrm{p} & =.032, \\
\text { Eta squared } & =.051\end{aligned}$ & $\begin{array}{l}\mathrm{F}=.272, \mathrm{p}=.603 \\
\text { Eta squared }=.002\end{array}$ \\
\hline Nurse technician & 9.45 & 70.22 \\
\hline Nurse & 13.72 & 67.20 \\
\hline Specialized nurse & 11.72 & 70.15 \\
\hline Head nurse & 11.24 & 68.44 \\
\hline ANOVA & $\begin{array}{l}\mathrm{F}=2.39, \mathrm{p}=.021 \\
\text { Eta squared }=.047\end{array}$ & $\begin{array}{l}\mathrm{F}=.333, \mathrm{p}=.801 \\
\text { Eta squared }=.007\end{array}$ \\
\hline Working relation $\leq 1$ year & 12.79 & 74.66 \\
\hline $1-3$ years & 12.67 & 65.55 \\
\hline 4-10 years & 14.67 & 62.00 \\
\hline $11-25$ years & 11.84 & 69.25 \\
\hline More than 25 years & 10.75 & 71.00 \\
\hline $\begin{array}{l}\text { Statistics of the } \\
\text { ANOVA }\end{array}$ & $\begin{array}{l}\mathrm{F}=2.39, \mathrm{p}=.043 \\
\text { Eta squared }=.062\end{array}$ & $\begin{array}{l}\mathrm{F}=2.391, \mathrm{p}=.05 \\
\text { Eta squared }=.062\end{array}$ \\
\hline Male assistants & 11.47 & 66.00 \\
\hline Female assistants & 12.46 & 68.48 \\
\hline ANOVA & $\begin{array}{l}\mathrm{F}=.316, \mathrm{p}=.575 \\
\text { Eta squared }=.02\end{array}$ & $\begin{array}{c}\mathrm{F}=.272, \mathrm{p}=.603 \\
\text { Eta square }=.02\end{array}$ \\
\hline Single & 13.06 & 68.36 \\
\hline Partnered & 8.93 & 69.20 \\
\hline
\end{tabular}

1 The bigger the number, the higher the burnout scores, i.e. the more numerous and the more frequent the burnout complaints.

2 The bigger the number, the better the well-being, i.e. the less depressive symptoms. 


\begin{tabular}{|c|c|c|}
\hline Category & $\begin{array}{l}\text { Mean score on the } \\
\text { burnout scale }(0-45)^{1}\end{array}$ & $\begin{array}{l}\text { Mean score on the WHO- } \\
5 \text { scale for depression } \\
(0-100)^{2}\end{array}$ \\
\hline ANOVA & $\begin{array}{l}\mathrm{F}=7.536, \mathrm{p}=.007 \\
\text { Eta squared }=.623\end{array}$ & $\begin{array}{l}\mathrm{F}=.798, \mathrm{p}=.066 \\
\text { Eta squared }=.000\end{array}$ \\
\hline Has nobody to rely on & 12.54 & 66.12 \\
\hline $\begin{array}{l}\text { Has at least one person to } \\
\text { rely on }\end{array}$ & 12.11 & 70.46 \\
\hline ANOVA & $\begin{array}{l}\mathrm{F}=.214, \mathrm{p}=.847 \\
\text { Eta squared }=.001\end{array}$ & $\begin{array}{l}\mathrm{F}=6.847, \mathrm{p}=.017 \\
\text { Eta squared }=.147\end{array}$ \\
\hline
\end{tabular}

For both measures of mental health, female assistants score somewhat worse than males, yet the differences are not significant. Singles report decidedly more burnout complaints than partnered nurses, and those socially isolated who have nobody to rely on have worse depression scores, i.e. they score lower on the WHO-5 scale.

Workload is significantly associated with burnout but not with depression. Analyses reveal the advantage - i.e. lower burnout scores - of nurses with shorter work time, but those performing in regular work time have the most burnout complaints. No further disadvantage of those working overtime is detected.

Systematic differences between categories reveal the disadvantages of the following groups: non-specialist medical assistants working in the outpatient care and not complete beginners but with an experience of 4 to 10 years in the profession. Sporadically, there are some further outliers; however, these associations are not systematic or are contradictory to the two indicators of mental health. For instance, home care assistants account for quite bad depression but also rather favourable burnout scores. However, their small number in the sample does not allow for generalization. Medical assistants working in the primary care (family practice nurses) are better-off with respect to both burnout and depression than the rest.

As far as the length of working relation and burnout are concerned, there seems to be no linear association between the two. Among those working for 1-3 years and 4-10 years in healthcare, the average burnout scores are higher, so that long years spent in healthcare seem to be protective against burnout. Further research is needed to clarify why exactly nurses with an employment relationship of 4 to 10 years have the worse mental health. Some mediatized scandals of the Romanian health system date back to the time of the career start of these health workers, and these might have led to considerable scepticism of the nurses towards their work. However, a more detailed analysis is needed in this respect.

Differences in organizational tenure are considerable. Medical assistants who perform healthcare work but are not specialized in a specific domain have even worse mental health scores than the auxiliary personnel not directly involved in caring activities. Specialization is largely related, however, not equal, to education and length of employment relationship and is reflected by income. 
Two-variable analysis results do not yet allow for far-reaching conclusions. In order to identify the agents that influence mental health adjusted to all covariates, two linear regression models are called upon, one for burnout and one for depression, which measure the pure impact of explanatory variables one by one, controlling for other effects.

Table 2. The determinants of burnout and depression. Linear regression, $N=301$

\begin{tabular}{lcccccc}
\hline Explanatory variables & $\mathbf{B}$ & $\mathbf{p}$ & $\boldsymbol{\beta}$ & $\mathbf{B}$ & $\mathbf{p}$ & $\boldsymbol{\beta}$ \\
\hline & \multicolumn{3}{c}{ Burnout $^{3}$} & \multicolumn{3}{c}{ Depression $^{4}$} \\
\hline Household income (deciles) & -0.157 & 0.000 & -0.148 & 0.246 & 0.000 & 0.248 \\
\hline $\begin{array}{l}\text { Partnership status (single }- \\
\text { partnered) }\end{array}$ & -0.673 & 0.000 & -0.146 & 3.173 & 0.000 & 0.205 \\
\hline $\begin{array}{l}\text { Number of intimate social } \\
\text { relations }\end{array}$ & -0.489 & 0.012 & -0.073 & 0.989 & 0.000 & 0.056 \\
\hline Number of working hours & 0.077 & 0.037 & 0.187 & 0.192 & 0.069 & 0.065 \\
\hline Gender (man - woman) & 0.117 & 0.052 & 0.022 & -0.717 & 0.002 & -0.042 \\
\hline Age & 0.006 & 0.615 & 0.013 & 0.032 & 0.432 & 0.018 \\
\hline $\begin{array}{l}\text { Activity domain: inpatient } \\
\text { service vs. home care }\end{array}$ & 0.042 & 0.213 & 0.156 & 0.087 & 0.223 & 0.892 \\
\hline $\begin{array}{l}\text { Activity domain: outpatient } \\
\text { service vs. home care }\end{array}$ & 0.721 & 0.000 & 0.137 & 0.721 & 0.324 & 0.087 \\
\hline $\begin{array}{l}\text { Activity domain: primary } \\
\text { care vs. home care }\end{array}$ & 0.022 & 0.431 & 0.082 & 0.031 & 0.331 & 0.121 \\
\hline Constant & 10.55 & 0.279 & & 67.10 & 0.198 \\
\hline & Adjusted $\mathrm{R}^{2}=0.112 ;$ & $\begin{array}{l}\text { Adjusted } \\
\mathrm{R}^{2}=0.089 ;\end{array}$ \\
\hline
\end{tabular}

The regression models are significant; the included occupational and sociodemographic explanatory variables account for $11 \%$ of the total variance of burnout symptoms (adjusted $\mathrm{R}^{2}=0.11$ ) and for $8.9 \%$ of the variance of depression (adjusted $\mathrm{R}^{2}=0.089$ ). The explanatory power is not too strong. However, this is an impressive result, especially if one considers that mental health is largely biologically and genetically determined.

On the basis of the absolute Beta (b) values, it can be stated that there are significant differences in the variables' effect upon mental health. That is, in the case of burnout, the most important explanatory variable is the number of working hours (standardized $b=0.187$ ), followed by household income (standardized $b=-0.148$ ) and partnership status (standardized $b=-0.146$ ). The number of intimate social relations also contributes to the inequalities in burnout scores among medical assistants. From

3 Bigger numbers mean more symptoms.

4 Bigger numbers mean better well-being, less depressive symptoms. 
the activity domains included as dummy variables, assistants working in outpatient healthcare settings have significantly worse burnout scores than the home care professionals chosen as reference category (standardized $b=0.137$ ).

For depression in general, the impact of financial status measured by income deciles is by far the strongest explanatory variable (standardized $b=0.248$ ). All other conditions being the same, the largest difference in the depression score of two people is located in their income differences. Moving upwards on the income scale, the well-being score measured on a 0 to 100 scale increases by as much as 0.246 units (unstandardized $\mathrm{B}=0.246$ ) compared to a person of the same age, gender, partnership status but being only one income level lower.

Income is by far the best predictor for depression: it explains in itself the biggest part of the variance of mental health. The second is partnership status (standardized $b=0.205$ ). Irrespective of the legal status of a partnership, its positive impact upon mental health is impressive and significant: living with a partner increases mental well-being by as much as three units (unstandardized $\mathrm{B}=3.173$ ), which implies a decrease in the depressive symptoms. Further, the number of intimate social relations is good for mental health. Last, gender in itself also impacts to some extent upon depression, so that controlled for all covariates, women have slightly worse mental health (unstandardized B $=-0.217$ ). Age in itself has no linear impact upon either burnout or depression scores.

\section{Discussion}

The novelty of this study is that it measures the pure impact of occupational, social, and demographic determinants upon the mental health of medical assistants. This professional group is heterogeneous by nature, however, being more uniform than healthcare professionals in general, including medical doctors and administrative staff, too, which most studies focus on.

Work-related features were introduced in our regression model in order to assess the impact of occupational hazards on mental health as the existing literature pleads for the primacy of occupational factors in determining especially burnout, but to a large extent depression as well (Alarcon 2011, Johari-Omar 2019). Indeed, among the occupational predictors, the number of working hours has the strongest impact upon burnout, but not upon depression. This finding might be new evidence for the debate on the overlap of burnout and depression in favor of distinguishing the two syndromes. Further, working in the outpatient activity domain was found to significantly impact upon burnout scores and to have quite a strong predictive power. However, activity domain is not related to depression.

As expected, our data sheds light on the strong social gradient of both syndromes. In accordance with the established knowledge on general populations (Hudson 
2005, Molarius et al. 2009, Hailemichael et al. 2019) and on healthcare professionals (Tachtsoglou et al. 2018), socio-economic status is a strong determinant of mental health: it is the second strongest determinant for burnout and the strongest one for depression. Those living on higher income report of the best mental health with respect to both burnout and depression. There is an inverse association between income and mental health: the higher the income decile a respondent belongs to, the less burnout symptoms he/she reports of, and the better his/her depression scores are. Each income category extracts 0.148 points from the burnout scores and adds 0.246 points to the WHO-5 well-being scale approximating depression (values of B for the respective scales). Considering two persons on the extreme poles of wealth, the difference in their depression scores is an impressive $(10-1)^{*} 0.24=$ 2.25 points on a 100-point scale. Our analysis measured socio-economic status not only by income but by organizational tenure as well. With all measurements alike, differences are revealed in burnout and depression, which are attributable to socioeconomic inequalities among medical assistants.

Then, being partnered improves mental health (standardized $b=-1.146$ and 0.205 ) by decreasing the number of burnout symptoms and increasing mental well-being considerably. The impact of partnership on health irrespective of marital status has already been identified in general populations by previous research (Sántha 2016). For medical assistants, it has been demonstrated that partnership and family serve as protective factors against burnout and depression (Ádám et al. 2015, Deutsch et al. 2015, Zarei et al. 2019, Molina-Praena et al. 2018).

Social integration significantly contributes to the improvement of both mental health indicators. In these models, social integration is measured by the number of intimate social relations. As far as the predictive power of social connections are concerned, studies indicate that people with high socio-economic status have more social resources and the number of their supportive friendships is higher (ChangGoldthorpe 2004), i.e. their social integration is stronger. However, a paradox was also pointed out - namely that among women with low resources social connections may actually increase the levels of mental illness symptoms since for them such ties entail role strain and obligations (Kawachi-Berkman 2001).

For the medical assistants participating in our study, social support ties are vitally important: intimate social relations contribute to mental health by decreasing burnout and depressive symptoms. Linear regression assesses the predictive power of social integration in itself, adjusted to the effect of other variables, and the results show that all other conditions being the same an increase by one unit in the number of friends - put simply, one friend more - decreases the number of burnout symptoms by as much as half a scale point (unstandardized B $=-0.489$ ) and increases the WHO-5 score with one scale point (unstandardized B $=0.989$ ), thus enhancing mental health considerably. The negative impact of social isolation upon mental health is in line with the findings of the vast majority of studies (Delaney et 
al. 2007, Freeney-Fellenz 2013, Deutsch et al. 2015, Bridgeman et al. 2018, MolinaPraena et al. 2018).

Our findings reinforce part of the well-established knowledge in gender health research, according to which women report more depression complaints than men (Waqas et al. 2015). Gender has a small but significant impact upon depression, the mental health of women assistants being slightly worse compared to that of men (unstandardized $\mathrm{B}=-0.717$ ). As for burnout, the literature is quite inconclusive in this respect as there are both findings that suggest more burnout symptoms among male assistants (Ádám et al. 2015) and studies that report similar burnout levels for both genders (Zarei et al. 2019). In Romanian medical assistants, when all occupational and social features are controlled for, gender does not influence burnout.

\section{Summary and Conclusions}

Our results are consistent with those revealed in international surveys, i.e. there are differences in mental health across education levels (in our case, measured by income), the number of working hours, and activity domain. Nurses in outpatient services report more burnout symptoms and worse mental health than those in other domains. Non-specialist medical assistants are disadvantaged compared to those specialized or holding head positions and even compared to the less skilled nurse technicians who are not in the front line of care activities. In Romania, for reasons worthy of future investigations, nurses employed for 4 to 10 years are the most exposed to burnout and depression.

Our analysis reveals a social gradient largely related to occupational and socioeconomic situation as well as to social capital variables. Partnership status and social capital reduce the number of burnout symptoms but have an even more beneficial impact by preventing depression in healthcare professionals.

This study brings some new evidence to the view that burnout and depression are two distinct syndromes as their determinants coincide only partly. Whereas burnout is more related to occupational factors such as extensive workload and activity domain within the healthcare system, depression is more strongly impacted by socio-economic status and, to some extent, gender. Although both syndromes are largely influenced by social features, burnout seems to be more situationally influenced whereas depression more structurally affected.

This study aimed at identifying structural and personal determinants of burnout and depression among nurses in Romanian state-owned healthcare institutions. There are, however, further important mediators such as work satisfaction, selfefficacy, control over work, or negative work-life interference. Our analysis does not consider these mediators for two reasons: First, due to theoretical considerations because we were aiming at finding the pure background variables not influenced 
by other factors and, second, due to technical issues as some of these plausible determinants were not measured by the questionnaire, or their measurement did not occur with standard scales.

One further limitation of the analysis is that in the data collection procedure hospital units were not differentiated as the questionnaire included only a question related to the wider activity domain of nurses. The cross-sectional survey design only allows for careful causal inferences between determinants and mental health.

\section{Acknowledgment}

The research was carried out with the support of Domus Group Scholarship of the Hungarian Academy of Sciences.

\section{References}

Ádám, Szilvia, Nistor, Anikó, Nistor, Katalin, Cserháti, Zoltán, Mészáros, Veronika. 2015. A kiégés és a depresszió diagnosztizálásának elősegítése demográfiai és munkahelyi védő és kockázati tényezőinek feltárásával egészségügyi szakdolgozók körében. Orvosi Hetilap 156(32): 1294-1303.

Ahola, Kirsi, Hakanen, Jari, Perhoniemi, Riku, Mutanen, Pertti. 2014. Relationship between Burnout and Depressive Symptoms: A Study Using the Person-Centred Approach. Burnout Research 1: 29-37.

Alarcon, Gene M. 2011. A Meta-Analysis of Burnout with Job Demands, Resources, and Attitudes. Journal of Vocational Behavior 79: 549-562.

Bakker, Arnold B., Schaufeli, Wilmar B., Demerouti, Evangelia, Janssen, Peter P. M., Van Der Hulst, Renée, Brouwer, Janneke. 2000. Using Equity Theory to Examine the Difference between Burnout and Depression. Anxiety Stress Coping 13: 247268.

Bakusic, Jelena, Schaufeli, Wilmar B., Claes, Stephan J., Godderis, Lode. 2017. Stress, Burnout and Depression: A Systematic Review on DNA Methylation Mechanisms. Journal of Psychosomatic Research 92: 34-44.

Bianchi, Renzo, Boffy, Claire, Hingray, Coreline, Truchot, Didier, Laurent, Eric. 2013. Comparative Symptomatology of Burnout and Depression. Journal of Health Psychology 18: 782-787.

Bianchi, Renzo, Schonfeld, Irvin Sam, Laurent, Eric. 2015. Burnout-Depression Overlap: A Review. Clinical Psychology Review 36: 28-41.

Borritz, Marianna, Villadsen, Ebbe, Christensen, Karl B. 2005. The Copenhagen Burnout Inventory: A New Tool for the Assessment of Burnout. Work and Stress 19(3): 192-207. 
Brewer, Ernest W., Shapard, Leslie. 2004. Employee Burnout: A Meta-Analysis of the Relationship between Age or Years of Experience. Human Resource Development Review 3(2):102-123.

Bria, Mara, Spânu, Florina, Băban, Adriana, Dumitraşcu, Dan L. 2013. Burnout among Romanian Healthcare Professionals: The Role of Work-Home Interference. Sociologie Românească 9(3): 85-98.

2014. Maslach Burnout Inventory - General Survey: Factorial Validity and Invariance among Romanian Healthcare Professionals. Burnout Research 1: 103111.

Bridgeman, Patrick J., Bridgeman, Mary Barna, Barone, Joseph. 2018. Burnout Syndrome among Healthcare Professionals. American Journal of Health-System Pharmacy 75: 147-152.

Chang, Tak Wing, Goldthorpe, John H. 2004. Is There a Status Order in Contemporary British Society? Evidence from the Occupational Structure of Friendship. European Sociological Review 20 (5): 383-401.

Delaney, Liam, Doyle, Orla, McKenzie, Kenneth, Wall, Patrick G. 2007. The Distribution of Wellbeing in Ireland. Dublin: UCD Geary Institute.

Demerouti, Evangelia, Bakker, Arnold B., Nachreiner, Friedhelm, Schaufeli, Wilmar B. 2001. The Job Demands-Resources Model of Burnout. Journal of Applied Psychology 86: 499-512.

Deutsch, Szilvia, Fejes, Enikő, Kun, Ágota, Medves, Dóra. 2015. A jóllétet meghatározó tényező́k vizsgálata egészségügyi dolgozók körében. Alkalmazott Pszichológia 15(2): 49-71.

Freeney, Yseult, Fellenz, Martin. 2013. Work Engagement as a Key Driver of Quality of Care: A Study of with Midwives. Journal of Health Organization and Management 27(3): 330-349.

Freudenberger, Herbert J., Richelson, Geraldine. 1980. Burn-Out: The High Cost of High Achievement. Garden City, NY: Anchor Press.

Gal, Melinda, Timofe, Mara Paula, Rus, Diana, Zavtochi, E. S., Boeriu, Cristian, Chereches, Răzvan M., Peek-Asa, Corinne. 2013. Emergency Health Care Violence: Who Is at Risk? Evidence from a Large Emergency Department in Mureş County, Romania. European Journal of Public Health 23, Supplement 1: 164.

Gascón, Santiago, Martínez-Jarreta, Begoña, González-Andrade, J. Fabrizio, Santed, M. Angél, Casalod, Yolanda, Rueda, M. Ángeles. 2009. Aggression towards Health Care Workers in Spain. International Journal of Occupational and Environmental Health 15(1): 32-33.

Glise, Kristina, Hadzibajramovic, Emina, Jonsdottir, Ingibjörg H., Ahlborg, Gunnar Jr. 2010. Self-Reported Exhaustion: A Possible Indicator of Reduced Work Ability and Increased Risk of Sickness Absence among Human Service Workers. International Archives of Occupational and Environmental Health 83(5): 511-520. 
Gonçalves, Alice, Fontes, Liliana, Simães, Clara, Gomes, Rui. 2019. Stress and Burnout in Health Professionals. In: Arezes, P. et al. (eds.), Occupational and Environmental Safety and Health. Springer. 563-571.

Green, Dianna E., Walkey, Frank H., Taylor, Antony J. W. 1991. The Three-Factor Structure of the Maslach Burnout Inventory: A Multicultural, Multinational Confirmatory Study. Journal of Social Behavior and Personality 6: 453-472.

Gupta, Manish, Shaheen, Musarrat S. 2018. Does Work Engagement Enhance General Well-Being and Control at Work? Mediating Role of Psychological Capital. Evidence-Based HRM: A Global Forum for Empirical Scholarship. https://doi. org/10.1108/EBHRM-05-2017-0027.

Hailemichael, Yohannes, Hanlon, Charlotte, Tirfessa, Kebede, Docrat, Sumaiyah, Alem, Atalay, Medhin, Girmay, Fekadu, Abebaw, Lund, Crick, Chisholm, Dan, Hailemariam, Damen. 2019. Mental Health Problems and Socioeconomic Disadvantage: A controlled Household Study in Rural Ethiopia. International Journal for Equity in Health 18: 121.

Hall, Louise H, Johnson, Judith, Watt, Ian, Tsipa, Anastasia, O'Connor, Daryl B. 2016. Healthcare Staff Wellbeing, Burnout, and Patient Safety: A Systematic Review. PLoS ONE 11(7): e0159015.

Hamdan, Motasem, Hamra, Asma'a Abu. 2017. Burnout among Workers in Emergency Departments in Palestinian Hospitals: Prevalence and Associated Factors. BMC Health Services Research 17: 407.

Harmat, György, Czárán, Erzsébet. 2008. Erőszak az egészségügyben. Egészségügyi Gazdasági Szemle 5: 34-35.

Häusler, Nadine, Bopp, Matthias, Hämming, Oliver. 2018. Effort-Reward Imbalance, Work-Privacy Conflict, and Burnout among Hospital Employees. Journal of Occupational and Environmental Medicine 60(4): e183-e187.

Hobfoll, Stevan E. 1989. Conservation of Resources. A New Attempt at Conceptualizing Stress. American Psychologist 44(3): 513-524.

Hobfoll, Stevan E., Shirom, Arie. 1993. Stress and Burnout in the Workplace: Conservation of Resources. In: Golembiewski, R. T. (ed.), Handbook of Organizational Behaviour. New York: M. Dekker. 41-60.

Hudson, Christopher G. 2005. Socioeconomic Status and Mental Illness: Tests of the Social Causation and Selection Hypotheses. American Journal of Orthopsychiatry 75(1): 3-18.

Irinyi, Tamás, Németh, Anikó. 2017. Az egészségügyi szakdolgozókat ért agresszív cselekmények kapcsolata szociodemográfiai és munkahelyi tényezőkkel. Orvosi Hetilap 158(6): 229-237.

Johari, Farah Shazlin, Omar, Rosmini. 2019. Exploring Factors Impacting on Psychological Well-Being of Health Care Workers. International Journal of Academic Research in Business and Social Sciences 9(2): 5672-5684. 
Kalliath, Thomas J., O’ Driscoll, Michael P., Gillespie, David F., Bluedorn, Allen C. 2000. A Test of the Maslach Burnout Inventory in Three Samples of Healthcare Professionals. Work and Stress 14: 35-50.

Kawachi, Ichiro, Berkman Lisa F. 2001. Social Ties and Mental health. Journal of Urban Health 78(3): 458-467.

Kleinbaum, David G., Kupper, Lawrence L., Nizam, Azhar, Rosenberg, Eli S. 2014. Applied Regression Analysis and Other Multivariable Methods ( $5^{\text {th }}$ ed.). Boston: Cengage Learning.

Koeske, Gary F., Koeske, Randi Daimon. 1989. Construct Validity of the Maslach Burnout Inventory: A Critical Review and Reconceptualization. The Journal of Applied Behavioral Science 25(2): 131-144.

Koutsimani, Panagiota, Montgomery, Anthony, Georganta, Katerina. 2019. The Relationship between Burnout, Depression, and Anxiety: A Systematic Review and Meta-Analysis. Frontiers in Psychology 10: 284.

Kumar, Amit, Bhat, Pookala Shivaram, Ryali, Sumalatha. 2018. Study of Quality of Life among Health Workers and Psychosocial Factors Influencing It. Industrial Psychiatry Journal 27(1): 97-102.

Loera, Barbara, Converso, Daniela, Viotti, Sara. 2014. Evaluating the Psychometric Properties of the Maslach Burnout Inventory-Human Services Survey (MBI-HSS) among Italian Nurses: How Many Factors Must a Researcher Consider? PLoS One 9(12): e114787.

Luciani, Michaela, Spedale, Valentina, Romanenghi, Monica, Villa, Candida Ester, Ausili, D., Di Mauro, Stefania. 2016. Atti di violenza verso gli infermieri e fattori associati alla violenza nel contesto ospedaliero: uno studio trasversale. Medicina del Lavoro 107(3): 191-204.

Makkai, Kinga. 2018. Evaluating the Level of Burnout among Healthcare Professionals. Acta Universitatis Sapientiae, Social Analysis 8: 23-39.

Malach-Pines, Ayala. 2000. Nurses' Burnout: An Existential Psychodynamic Perspective. Journal of Psychosocial Nursing and Mental Health Services 38(2): 23-31.

Maslach, Christina, Jackson, Susan E. 1986. Maslach Burnout Inventory Manual $\left(2^{\text {nd }}\right.$ ed.). Palo Alto, CA: Consulting Psychologists Press.

Maslach, Christina, Schaufeli, Wilmar B., Leiter, Michael P. 2001. Job Burnout. Annual Review of Psychology 52: 397-422.

Mészáros, Veronika, Ádám, Szilvia, Szabó, M, Szigeti, Réka, Urbán, Róbert. 2013. The Bifactor Model of the Maslach Burnout Inventory-Human Services Survey (MBI-HSS): An Alternative Measurement Model of Burnout. Stress and Health 30: 82-88.

Molarius, Anu, Berglund, Kenneth, Eriksson, Charli, Eriksson, Hans G., LindénBoström, Margareta, Nordström, Eva, Persson, Carina, Sahlqvist, Lotta, Starrin, Bengt, Ydreborg, Berit. 2009. Mental Health Symptoms in Relation to Socio- 
Economic Conditions and Lifestyle Factors - A Population-Based Study in Sweden. BMC Public Health 9(302): 1-9.

Molina-Praena, Jesús, Ramirez-Baena, Lucia, Gómez-Urquiza, José L., Cañadas, Gustavo R., De la Fuente, Emilia, Cañadas-De la Fuente, Guillermo A. 2018. Levels of Burnout and Risk Factors in Medical Area Nurses: A Meta-Analytic Study. International Journal of Environmental Research and Public Health 15: 2800.

Palenzuela, Patricia, Delgado, Naira, Rodriguez, José A. 2019. Exploring the Relationship between Contextual Performance and Burnout in Healthcare Professionals. Journal of Work and Organizational Psychology 35: 115-121.

Pálfi, Ilona, Németh, Katalin Anna, Kerekes, Zsuzsanna, Kállai, János, Betlehem, József. 2008. The Role of Burnout among Hungarian Nurses. International Journal of Nursing Practice 14: 19-25.

Rahimnia, Fariborz, Sharifirad, Mohammad S. 2015. Authentic Leadership and Employee Well-Being: The Mediating Role of Attachment Insecurity. Journal of Business Ethics 132(2): 365-377.

Randall, Kelvin J. 2007. Examining the Relationship between Burnout and Age among Anglican Clergy in England and Wales. Mental Health, Religion and Culture 10(1): 39-46.

Rehm, Jürgen, Shield, Kevin D. 2019. Global Burden of Disease and the Impact of Mental and Addictive Disorders. Current Psychiatry Reports 21(2):10.

Rodwell, John, Munro, Louise E. 2013. Well-Being, Satisfaction and Commitment: The Substitutable Nature of Resources for Maternity Hospital Nurses. Journal of Advanced Nursing 69(10): 2145-2372.

Rotilă, Viorel, Celmare, Lidia, Ciobanu, Georgiana, Palade, Traian. Lungu, Laurențiu. 2014. Cariere în sănătate: Oportunități şi piedici. Studiu privind nevoile specifice de consiliere şi orientare profesională ale salariaților din sănătate. Analiză de caz: Regiunea Bucureşti - Ilfov. Galați: Sodalitas.

Rotilă, Viorel, Ciobanu, Georgiana, Celmare, Lidia, Palade, Traian, Tetiva, Elena, Andoniu, Loredana. 2016. Calitatea vieții profesionale a salariaților din sănătate. Studii, analize şi demersuri privind unii dintre indicatori. Galați: Sodalitas.

Roy-Byrne Peter R., Joesch, Jutta M., Wang Philip S, Kessler Ronald C. 2009. Low Socioeconomic Status and Mental Health Care Use among Respondents with Anxiety and Depression in the NCS-R. Psychiatric Services 60(9): 1190-1197.

Sántha, Ágnes Rózsa. 2016. Social, Demographic and Labour Market Related Determinants of Health in the Adult European Population. Finnish Yearbook of Population Research 51: 77-88.

Shanafelt, Tait D., Boone, Sonja, Tan, Litjen, Dyrbye, Lotte N., Sotile, W., Satele, Daniel, West, Colin P., Sloan, Jeff, Oreskovich, Michael R. 2012. Burnout and Satisfaction with Work-Life Balance Among US Physicians Relative to the General US Population. Archives of Internal Medicine 172(18): 1377-1385. 
Schaufeli, Wilmar B., Enzmann, Dirk. 1998. The Burnout Companion to Study and Practice: A Critical Analysis. Philadelphia: Taylor \& Francis.

Schaufeli, Wilmar B., Greenglass, Esther R. 2001. Introduction to Special Issue on Burnout and Health. Psychology and Health 16: 501-510.

Spânu, Florina, Băban, Adriana, Bria, Mara, Lucăcel, Raluca, Dumitras, Dan L. 2013. A Study of Health Professionals' Burnout and Quality of Care in Romania. Procedia - Social and Behavioral Sciences 84: 1149-1153.

Suñer-Soler, Rosa, Grau-Martín, Armand, Font-Mayolas, Silvia, Gras, M. Eugenia, Bertran, C. Sullman, Mark J. M. 2013. Burnout and Quality of Life among Spanish Healthcare Personnel. Journal of Psychiatric and Mental Health Nursing 20: 305313.

Tachtsoglou, Kiriaki, Lera, Maurizio, Iliadis, Christos, Frantzana, Aikaterini, Kourkouta, Lambrini. 2018. Occupational Burnout of Health Care Professionals in Hospitals. Journal of Healthcare Communications 3(3):38.

Tizón, Jorge L. 2004. Burn-Out Professionals, Disillusioned Professionals or Professionals with Psycho-Pathological Disorders? Atención Primaria 33: 326330.

Toker, Sharon, Biron, Michal. 2012. Job Burnout and Depression: Unraveling Their Temporal Relationship and Considering the Role of Physical Activity. Journal of Applied Psychology 97: 699.

Topp, Christian Winter, Østergaard, Søren Dinesen, Søndergaard, Susan, Bech, Per. 2015. The WHO-5 Well-Being Index: A Systematic Review of the Literature. Psychotherapy and Psychosomatics 84: 167-176.

Van de Velde, Sarah, Bracke, Piet, Levecque, Katia, Meuleman, Bart. 2010a. Gender Differences in Depression in 25 European Countries after Eliminating Measurement Bias in the CES-D 8. Social Science Research 39(3): 396-404.

Van de Velde, Sarah, Bracke, Piet, Levecque, Katia. 2010b. Gender Differences in Depression in 23 European Countries. Cross-National Variation in the Gender Gap in Depression. Social Science \& Medicine 71: 305-313.

Vingender, István, Szalóczy, Nóra, Pálvölgyi, Miklós. 2018. The Structural Components of the Situation of Nurses in Hungary. Developments in Health Sciences 1(2): 49-55.

Visser, Mechteld R. M., Smets, Ellen M. A., Oort, Frans J., De Haes, Hanneke C. J. M. 2003. Stress, Satisfaction and Burnout among Dutch Medical Specialists. CMAJ: Canadian Medical Association Journal 168: 271-275.

Waqas, Ahmed, Ahmad, Waqas, Haddad, Mark, Taggart, Frances M., Muhammad, Zerwah, Bukhari, Muhammad Hamza, Sami, Shahzad Ahmed, Batool, Sayyeda Mehak, Najeeb, Fiza, Hanif, Ayesha, Rizvi, Zehra Ali, Ejaz, Sumbul. 2015. Measuring the Well-Being of Health Care Professionals in the Punjab: A Psychometric Evaluation of the Warwick-Edinburgh Mental Well-Being Scale in a Pakistani Population. PeerJ 3: e1264 
Wheeler, Denna L., Vassar, Matt, Worley, Jody A., Barnes, Laura L. B. 2011. A Reliability Generalization Meta-Analysis of Coefficient Alpha for the Maslach Burnout Inventory. Educational and Psychological Measurement 71: 231-244.

WHO. 1998. Wellbeing Measures in Primary Health Care/The DepCare Project. Copenhagen: WHO Regional Office for Europe.

Zander, Britta, Aiken, Linda H., Busse, Reinhard, Rafferty, Anne Marie, Sermeus, Walter, Bruyneel, Luk. 2016. The State of Nursing in the European Union. Eurohealth 22(1): 3-6.

Zarei, Ehsan, Ahmadi, Fariba, Sial, Muhammad Safdar, Hwang, Jinsoo, Thu, Phung Anh, Usman, Sardar Muhammad. 2019. Prevalence of Burnout among Primary Health Care Staff and Its Predictors: A Study in Iran. International Journal of Environmental Research and Public Health 16: 2249.

Ziegler, Matthias, Bensch, Doreen. 2013. Lost in Translation: Thoughts regarding the Translation of Existing Psychological Measures into Other Languages. European Journal of Psychological Assessment 29: 81-83.

Zubairi, Akbar Jaleel, Noordin, Shahryar. 2016. Factors Associated with Burnout among Residents in a Developing Country. Annals of Medicine and Surgery 6: $60-63$. 